\title{
Rare invasive mold infections in Greece; registry and analysis of cases from January 2014 - December 2017
}

\section{Drogari-Apiranthitou ${ }^{1}$, A. Bakossi ${ }^{1}$, A. Skiada ${ }^{2}$, G. Petrikkos ${ }^{1,3}$}

${ }^{1}$ Infectious Diseases Research Laboratory, 4th Department of Internal Medicine, University General Hospital "Attikon", 2 General Athens Hospital "Laiko", Medical School, National and Kapodistrian University of Athens, Greece, ${ }^{3}$ School of Medicine, European University

Cyprus, Nicosia, Cyprus

\section{OBJECTIVES}

National registries are important and necessary for the study and monitoring of rare invasive mold infections.

Our group has started a multicentre registry in Greece since 2005, along with the ECMM/ISHAM Global Registry initiative for zygomycosis (mucormycosis) (www.zygomyco.net).

The aim of the present study was:

- to determine the epidemiology of serious rare mold infections in Greece during the years 2014-2017, and the organisms involved

- to analyze any associations between the isolated fungi and clinical presentation, underlying diseases, risk factors and outcome

Table: Distribution of cases according to infectious agents

\begin{tabular}{|c|c|c|c|}
\hline Organism & $\mathbf{N}$ & Isolation site & underlying conditions \\
\hline Mucorales & 16 & & \\
\hline Rhizopus arrhizus & 9 & $\begin{array}{l}6 \text { sinus, } 1 \text { dissemin. } \\
\text { (knee/lung), } 1 \text { lung, } 1 \\
\text { urine }\end{array}$ & $\begin{array}{l}3 \text { haematologic malignancy, } 1 \text { DM*, } 2 \text { SO } \\
\text { Ca/DM, } 1 \text { MDS, } 1 \text { IgA nephropathy/ } \\
\text { steroid-related DM, } 1 \text { ureterostomia }\end{array}$ \\
\hline Lichtheimia spp. & 2 & soft tissue/skin, & 1 burns, 1 traffic accident \\
\hline Mucor spp. & 1 & $\begin{array}{l}\text { bronchial /gastric } \\
\text { secretions, }\end{array}$ & $\begin{array}{l}{ }^{*} \text { Child with hydrocephalus and shunt, } \\
\text { after intubation following status } \\
\text { epilepticus. }\end{array}$ \\
\hline unidentified genus & 1 & brain tissue & traffic accident \\
\hline no growth & 3 & 1 sinus, 1 lung, 1 skin & $1 \mathrm{DM}, 1 \mathrm{Ca}, 1$ flooding victim \\
\hline Fusarium & 13 & & \\
\hline F. proliferatum & 1 & cornea & eye injury \\
\hline F. solani & 1 & blood & haematol. malignancy \\
\hline F. dimerum & 1 & blood & haematol. malignancy \\
\hline Fusarium spp. & 10 & $\begin{array}{l}4 \text { cornea, } 4 \text { blood, } 2 \\
\text { skin }\end{array}$ & $\begin{array}{l}4 \text { keratitis ( } 1 \text { eye injury, } 1 \text { contact lens, } 1 \\
\text { after herpes infection, } 1 \text { ?), } 2 \text { ARDS, } 1 \text { brain } \\
\text { injury, } 1 \mathrm{HSCT}, 2 \text { leg injury }\end{array}$ \\
\hline $\begin{array}{l}\text { Purpureocillium } \\
\text { lilacinum }\end{array}$ & 2 & keratitis & eye injury \\
\hline $\begin{array}{l}\text { Scedosporium } \\
\text { apiospermum SC }\end{array}$ & 1 & bronchial secretions, & HSCT \\
\hline Alternaria spp. & 2 & keratitis & 1 contact lens, 1 ? \\
\hline Bipolaris spp. & 1 & $\mathrm{BAL}$ & AML relapse, neutropenia \\
\hline
\end{tabular}

\section{MATERIALS AND METHODS}

Prospective, observational, non-interventional, nationwide clinical and laboratory study (ongoing).

Patient material, data and available strains were sent to our laboratory for laboratory diagnosis, recording, fungal identification and antifungal susceptibility testing whenever needed (EUCAST broth microdilution methodology).

In cases with no fungal growth, formalin fixed and paraffin embedded (FFPE) tissues were collected for histopathological and molecular analysis.

\section{ACKNOWLEDGEMENTS}

The study was financially supported by a grant from GILEAD (ASKLEPIOS Programme, 2013)

\section{RESULTS}

New cases number (N): 35, of which 16 due to Mucorales, 13 due to Fusarium, and 6 due to other rare molds: Purpureocillium lilacinum (2), Scedosporium apiospermum species complex (SC) (1), Alternaria (2) and Bipolaris (1) (Table). The frequency of cases was 8.7/year, comparable to that of previous years.

Mucorales (14 proven, 2 possible, EORTC/MSG criteria). Most cases with Rhizopus arrhizus were from patients with rhino-orbitocerebral mucormycosis. More frequent underlying conditions: hematologic malignancy, diabetes mellitus (DM) and soft tissues/skin after serious injuries following accidents (Fig. 1 a, b).

The 2 Lichtheimia species were isolated from soft tissues from patients with severe trauma after road accidents.

${ }^{\star}$ Case Fatality Rate for mucormycosis: $\mathbf{5 0 \%}$.
The Fusarium strains were isolated from blood cultures of severely ill patients, and from corneal or skin ulcers of immunocompetent, after trauma (Table and Fig. 2 a, b).

Fig. 1

$$
\begin{aligned}
& \text { a. Mucormycosis isolation } \\
& \text { sites }
\end{aligned}
$$
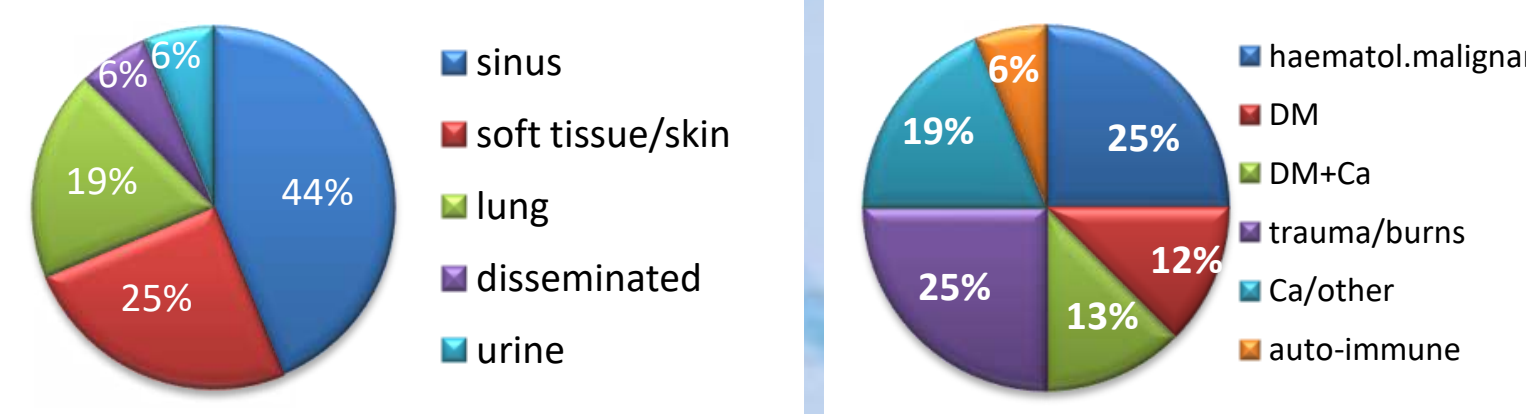

Fig. 2

a. Fusariosis isolation sites

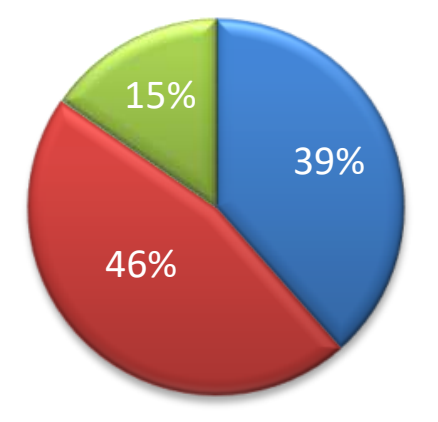

cornea

blood

$\square$ skin b. Fusariosis underlying conditions

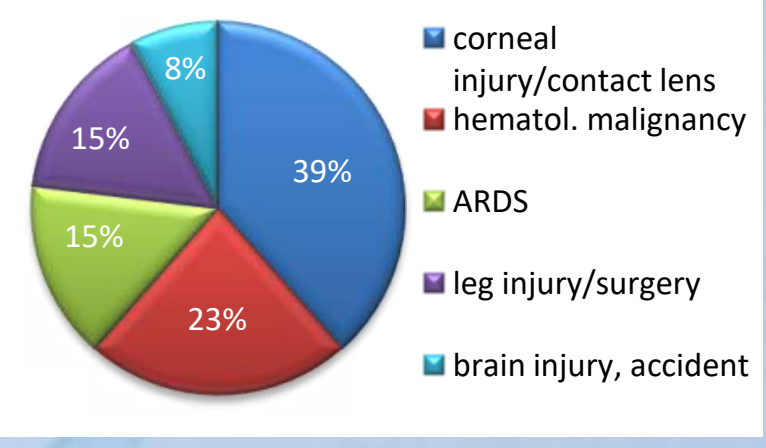

\section{CONCLUSIONS}

Rare invasive mold infections remain rare in our region.

More prominent are: mucormycosis in patients with haematologic malignancies, diabetes and trauma, and fusariosis in keratitis cases and severely ill patients.

Ocular trauma and soft contact lens use are also important risk factors for keratitis due to other rare molds.

\section{REFERENCES}

1. Skiada A, Pagano L, Groll A, et al.: Zygomycosis in Europe: analysis of 230 cases accrued by the registry of the European Confederation of Medical Mycology (ECMM) Working Group on Zygomycosis between 2005 and 2007. Clin Microbiol Infect. 2011; 17: 1859-67.

2. Tortorano, A.M. et al. Confederation of Medical Mycology (ECMM) epidemiological survey on invasive infections due to Fusarium species in Europe. Eur J Clin Microbiol Infect Dis 2014; 33: 1623-1630.

3. Skiada A, Pavleas I, Drogari-Apiranthitou M. Rare fungal infectious agents: a lurking enemy. F1000Res. 2017; 6:1917. 